toe angle increased with advancing age by about $2^{\circ}$ every 10 years. This gave rise to the question whether all feet showed increasing distortion with advancing age or whether only deformed feet became distorted. Later surveys strongly suggested that if a woman could reach the age of 20 years with a bigtoe angle of less than $10^{\circ}$ she was unlikely to develop bunions in old age. He listed the various factors which were of importance in the construction of shoes and said that of these shoe-shape was certainly the most significant item. It was thought that for teenage children a big-toe angle of $10^{\circ}$ was a reasonable compromise between fit and fashion; unfortunately few of to-day's teenage shoes fell within this limit. $\mathrm{He}$ put in a plea for more foot-health education in junior schools.

\section{Necessity for Standardization}

Mr. Duncan Neal, formerly a director of Daniel Neal, spoke of problems in the retail trade. He thought there were several directions in which improvement might be obtained. There should be better education of retail managements as well as of parents and of schoolchildren themselves. There should also be standardization of shoe sizes. Many school principals were in favour of uniform shoes in schools but had not the power to enforce them. In any case uniform for school wear would have to be backed by an efficient retail service if it was to be successful. The time was overdue for standards to be laid down for length and width of shoes and for this to be enforced by legislation. Mrs. Helen B. Gordon, speaking as a parent, advanced three proposals which she believed would be practical. First, shoes should be approved by a recognized authority and clearly marked as such. Secondly, schools should be adamant about the kind of shoes worn at school. Thirdly, there was need for more information on the effect of bad shoes.

Mr. D. Grimway, of the Shoe and Allied Trades Research Association, spoke of the surveys which his association carried out on the health of children's feet. The result of this work had been the production of a range of children's lasts to suit the foot at each stage of development. One of the problems was to cater for non-average feet; this was mainly done by making shoes in sizes and half-sizes and sometimes in different fittings. A proposed new system without half-sizes would cater for nearly $90 \%$ of children with quite a high standard of fit, but this had not been used commercially. Mr. J. L. HANLEY, of James Southall \& Co. Ltd., said that this conference was welcomed by the manufacturers. Good results and improved foot health could be achieved only by a cooperative effort with retailers, the medical profession, chiropodists, and educational authorities. One of the great limitations was the lack of public interest in the subject. The ideal place for foot-health education was in the school.

Dr. MARY Gorrie (Ministry of Health) spoke of the work that had been done in health education over the past 20 years. Much education and preventive work had been carried out by the Central Council for Health Education, by local education authorities, and by local health authorities. Where a worthwhile programme of activities was planned sufficient interest could be aroused to produce good results.

\section{Proposals for the Future}

The final speaker was Mr. T. E. Stamm (Guy's Hospital), who made some proposals for the future. In the first place there should be a foot-care service, at least equivalent to that given for children's teeth. Mr. Stamm was also convinced that control over the shoes worn by children in schools was essential. There were obvious difficulties, but these must be overcome. He suggested also a stamp of authorization similar to that carried by utility articles in the rationing period, together with legislation which required that only acceptable shoes should be worn. The third proposal was that all approved shoes should be free of purchase tax. Lastly, as had been emphasized by other speakers, education measures were of the utmost importance.

After some considerable discussion from the floor, the following recommendations were adopted for submission to H.M. Government, through the Council of the B.M.A.:

(a) A school foot-care service should be established; this service to include regular inspection of children's feet and footwear.

(b) There should be control of footwear worn for school; this footwear to be of approved design.

(c) All footwear approved, as above, to be free of purchase tax.

(d) That the Government be requested to increase its efforts of health education in this connexion.

\title{
NEW APPLIANCES
}

\section{Splint for Mallet-finger}

Dr. J. M. Abouna, surgical registrar, Royal Victoria Infirmary, Newcastle upon Tyne, writes: A variety of gadgets have been described from time to time for treatment of mallet-finger. Most of these are therapeutically ineffective, uncomfortable to wear, and difficult to apply. In consequence, treatment is sometimes abandoned by both patient and doctor.

The splint here described was designed to overcome some of these difficulties. It consists of spring-steel wire size 16 s.w.G. The wire is moulded to the shape illustrated in Fig. 1, the essential features being a straight cross-bar at the distal end and a semicircular loop at the proximal end. Between these there are dorsal and ventral semicircular flanges which can be opened or closed according to the size of the finger.

After being shaped the splint is dipped in latex rubber to give it a soft and smooth outer shell. In use, the affected finger is simply passed through the splint so that the cross-bar at one end presses against the distal pulp and the two semicircular flanges embrace the distal interphalangeal joint, which is thus maintained in hyperextension (Fig. 2). To take account of the varying dimensions of individual fingers in both adults and children, the splint is made in three different sizes.

The appliance has been used with gratifying results in the Hand Clinic of the Royal Victoria Infirmary, Newcastle upon Tyne, for mallet-fingers caused by closed injuries.

The advantages which can be claimed for this splint are: (1) ease and cheapness of construction; (2) it fits on the finger as a light spring without the use of tapes or bandages; (3) the diameter of each splint, and thus the tension in the spring flanges, can be varied by separating the opposing flanges to suit fingers of differing diameters ; (4) it is comfortable to the patient and has been worn continuously for four weeks, followed by use at night only during the succeeding month ; (5) the patient is able to continue to use the hands for ordinary daily activity, including frequent washing, without hindrance; and (6) the same splint can be used a number of times for different patients.
The splint is manufactured and supplied by Messrs. Peacocks (S.M.E.) Ltd., Friar House, Clavering Place, Newcastle upon Tyne. I am grateful to Mr. John Walden,

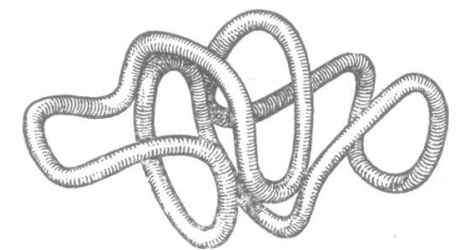

FIG. 1

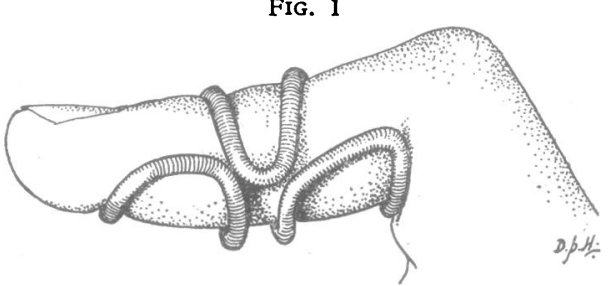

FIG. 2

of Peacocks Ltd., for his help in making the appliance ; and to Mr. Douglas Hammersley, medical artist, Department of Surgery, University of Newcastle upon Tyne, for the drawings. 